\title{
Relationship between serum inflammatory cytokines and lifestyle factors in gastric cancer
}

\author{
XIAN SUN ${ }^{1}$, CHUN-JIE XIANG ${ }^{1}$, JUAN WU ${ }^{1}$, WEI DONG ${ }^{1}$, \\ ZHEN ZHAN $^{1}$, RUI-PING WANG ${ }^{2,3}$ and JUN-FENG ZHANG ${ }^{1}$
}

${ }^{1}$ Department of Pathogen and Immunology, School of Medicine and Life Sciences, Nanjing University of Chinese Medicine, Nanjing, Jiangsu 210023; ${ }^{2}$ Department of Oncology, First Affiliated Hospital of Nanjing University of Chinese Medicine; ${ }^{3}$ Department of Oncology, Jiangsu Province Hospital of Traditional Chinese Medicine, Nanjing, Jiangsu 210029, P.R. China

Received July 25, 2018; Accepted January 15, 2019

DOI: $10.3892 / \mathrm{mco} .2019 .1804$

\begin{abstract}
Chronic inflammation is associated with increased risk of gastric cancer (GC), and GC risk is significantly associated with lifestyle. The aim of the present study was to explore the association between serum inflammatory cytokines and lifestyle factors in GC. A total of 20 serum inflammatory cytokines were measured in a hospital-based case-control population with $142 \mathrm{GC}$ patients and 98 healthy controls. Controls without the selected healthy lifestyle factors were regarded as baseline, and correlation analysis was conducted to establish the association between serum inflammatory cytokines and lifestyle factors. The results demonstrated that several lifestyle factors (including eating fried and salty foods, eating quickly, smoking and drinking) could increase the risk of GC, while only eating fresh fruits could decrease the risk of GC. Correlation analysis revealed that increased serum interleukin (IL)-12/IL-23P40 levels was associated with GC risk as significant differences were observed in all lifestyle factors. Increased serum IL-8 was closely associated with smoking in GC patients, while increased IL-17 $\alpha$ and IL- 8 levels were associated with GC patients who ate salty foods. Increased IL-10 and decreased TGF- $\beta$ levels were also associated with GC patients who ate fresh fruits. In conclusion, GC risk was strongly affected by lifestyle factors, which may regulate the expression of inflammatory cytokines and promote gastric carcinogenesis.
\end{abstract}

\section{Introduction}

Gastric cancer (GC) is one of the common leading cancers in the world (1). Especially in China, GC is still one of the

Correspondence to: Professor Jun-Feng Zhang, Department of Pathogen and Immunology, School of Medicine and Life Sciences, Nanjing University of Chinese Medicine, 138 Xianlin Avenue, Mail Box 21, Nanjing, Jiangsu 210023, P.R. China

E-mail: zhangjunfeng5_5@163.com

Key words: gastric cancer, inflammatory cytokine, lifestyle most common causes of death though the age-standardized death rates (per 100,000 people) fell significantly from 1990 to 2013 with the onset of rapid economic growth. Gastric carcinogenesis is a multi-stage, multi-factorial process. GC risk was closely related to many factors such as environmental Helicobacter pylori $(\mathrm{Hp})$ infection and heredity, and involved a variety of immune and molecular mechanisms. Since accumulating evidences suggest that chronic inflammation is an important component of the tumor microenvironment and represents the 7 th hallmark of cancer (2), more attention was paid on the inflammatory characteristics during the progression of GC development.

The cancer-related immune response was modulated by the inflammatory environment, which included tumor cells, epithelial/endothelial cells, leukocytes, and cytokines. Of them, cytokines were a crowd of heterogeneously soluble polypeptides/glycoproteins, and they could regulate tumor growth and metastasis, cause discomfort symptoms and potentially influence the tumor prognosis (3). Many studies had examined the associations among GC and the expression of inflammatory cytokines [vascular endothelial growth factor (VEGF), interleukin (IL)-1 $\beta$, IL-8, IL-10, IL-6, and granulocyte-macrophage colony-stimulating factor (GM-CSF)] (4-7), or the genetic variation of inflammatory cytokines [(IL-1 $\beta$, IL-12p40 and tumor necrosis factor- $\alpha$ $(\mathrm{TNF}-\alpha)](8,9)$.

Many epidemiological literatures had demonstrated that lifestyle was the most important etiological factor implicating in gastric carcinogenesis in the previous review (10) because lifestyle could deeply affect the body metabolism, for example, alcohol consumption and cigarette smoking were observed to be closely related to low plasma levels of ascorbic acid and vitamin $\mathrm{E}$ in the GC patients (11). Furthermore, previous investigation showed that the GC-risk-related lifestyle still remain unchanged in the east China during the past decades (12). Namely, GC risk was closely correlated to high intake of salted or fried foods, dried fish and meat, eating fast, smoking and drinking, while fresh fruits and tea played a protective role in the high incidence area of east China. Some studies suggested that lifestyle factors play an important role in triggering the development of GC, such as preferring to salty foods, smoking and drinking $(13,14)$. These results indicated that 
lifestyle shape the human metabolism and inflammation, for instance, a nationwide case-control study showed that lifestyle related inflammation was associated with an increased risk of oesophageal cancer, regardless of histological type (15).

However, the linking mechanism between lifestyle and GC risk was still unknown. Thus, the present study investigated the relationship between 20 serum inflammatory cytokines and lifestyle factors in a population of GC patients, and the results will provide some valuable clues for the underlying inflammatory mechanism between GC risk and lifestyle.

\section{Materials and methods}

Samples from patients and controls. This study was performed in accordance with Good Clinical Practice, followed applicable patient privacy requirements, and conformed to the Declaration of Helsinki. The research protocol was approved by the Ethics Committee of Jiangsu Province Hospital of Traditional Chinese Medicine (TCM) (Jiangsu, China) (no. 2015NL-016-01). All subjects were genetically unrelated ethnic Han Chinese. A total of $142 \mathrm{GC}$ patients were consecutively recruited in Jiangsu province, eastern China, from January 2015 to December 2016. At the same time, 98 volunteers were recruited as healthy controls at Jiangsu Province Hospital of TCM. A standard questionnaire was administered by trained interviewers to obtain clinical and demographic information. After signing informed consent documentation, a venous blood sample (3-5 ml) was collected from each subject on an empty stomach. Serum was obtained by centrifugation at 3,000 x $\mathrm{g}$ for $10 \mathrm{~min}$ and then stored at $-80^{\circ} \mathrm{C}$.

Inclusion criteria were as follows: i) Age $>30$ years; ii) Han Chinese ethnicity (self-reported); iii) resident of Jiangsu Province; iv) lack of previous malignant tumors in other organs; v) no severe heart failure, pulmonary insufficiency, or kidney disease; and vi) willing to cooperate. The following were excluded: i) Aged <30 years; ii) not resident in Jiangsu Province; iii) not Han Chinese (self-reported); iv) other malignant tumors; v) severe cardiovascular disease, pulmonary insufficiency, or kidney disease; vi) severe digestive system diseases (self-reported); and vii) unwilling to cooperate.

Integral scores of lifestyle factors. Since it is scarcely possible to collect individuals without any unhealthy lifestyles as controls, and GC patients are not likely to have all kinds of unhealthy lifestyles, here tried to use the lifestyle score to assess the realistic effect of lifestyle factors on GC risk. The GC-protective lifestyle factors were marked as minus one point, while the GC-risky lifestyle factors were marked as one point. And each individual got an integral score of lifestyle factors.

Measurement of inflammatory cytokines. Measurement of inflammatory cytokines was performed in strict accordance with the kit instructions, as previously described (16). In brief, stored serum samples were allowed to stand for $30 \mathrm{~min}$ at room temperature $\left(23^{\circ} \mathrm{C}\right)$ and then assayed in a single batch using Meso Scale Discovery (MSD, Gaithersburg, MD, USA) multiplex cytokine measurement techniques. Cytokine levels in serum were measured using the MSD Sector Imager 2400 (MSD), which allows up to ten cytokines to be measured simultaneously and with high sensitivity in specially coated 96-well plates. The technology is similar to a sandwich enzyme-linked immunosorbent assay (ELISA) in that a spot on the base of each plate is pre-coated with a capture antibody specific for each cytokine. When serum samples are incubated in the multi-spot plate, each cytokine binds to its corresponding capture antibody. A cytokine-specific detection antibody labeled with a light-emitting moiety is then added and cytokine levels are quantified using a charge coupled device camera. A pre-literature research indicated that many cytokines show significant changes in GC patients, and two kits were selected: The Pro-inflammatory Pane 11 (human) (cat. no. N05049A-1; MSD) kit, which detects IFN- $\gamma$, IL-1 $\beta$, IL-2, IL-4, IL-6, IL-8, IL-10, IL-12p70, IL-13, and TNF- $\alpha$, and the Cytokine Panel 1 (human) (cat. no. N05050A- 1;MSD) kit, which detects GM-CSM, IL-1 $\alpha$, IL-5, IL-7, IL-12/23 p40, IL-15, IL-16, IL-17 $\alpha$, TNF- $\beta$, and VEGF. To guarantee the sensitivity and reliability of each measurement, each assay included six spots that comprised a standard concentration gradient, along with one blank spot and one negative spot. A self-parametric fitting algorithm was used to calculate the concentration of each cytokine using software supplied with the MSD Sector Imager 2400. To guarantee the data's reliability, three samples were randomly tested in duplicate; inter-assay coefficients of variation for the 20 cytokines were $2-15 \%$.

Statistical analysis. Data was presented by mean \pm standard deviation if data was normally distributed such as age. Chi-square test was used for the rank data such as sex and lifestyle factors. Since the cytokine levels were not normally distributed, the median (interquartile) was presented. Data of serum cytokines was preprocessed as previously described (17) non-parametric test and logistic regression analysis were conducted for data processing. All statistical analyses were conducted using SPSS software, version 21.0 (IBM Corp., Armonk, NY, USA). All P-values were two-sided. $\mathrm{P}<0.05$ was considered to indicate a statistically significant difference.

\section{Results}

Common characteristics of the study subjects. The demographic characteristics between GC patients and controls were well matched by sex and age (Table I). Five lifestyle factors (i.e., prefer to fried foods, to salty foods, to eating fast, to smoking, to drinking and to fresh fruits) were significantly correlated to GC risk $(\mathrm{P}<0.05)$, but here did not observe significant correlation between preferring to tea and $\mathrm{GC}$ risk $(\mathrm{P}>0.05)$.

The differences of serum inflammatory cytokines between the GC patients and controls. The rates of detectable concentrations of the 20 inflammatory cytokines were as following: GM-CSF (227/240, 94.6\%), IL-1 $\alpha$ (149/240, 62.1\%), IL-5 (171/240, 71.3\%), IL-7 (239/240, 99.6\%), IL-12/IL-23P40 (239/240, 99.6\%), IL-15 (240/240, 100\%), IL-16 (240/240, $100 \%)$, IL-17 $\alpha$ (240/240, 100\%), TNF- $\beta$ (240/240, 100\%), VEGF $(240 / 240,100 \%)$, IFN- $\gamma(240 / 240,100 \%)$, IL-1 $\beta$ (135/240, 56.3\%), IL-2 (223/240, 92.9\%), IL-4 (177/240, $73.8 \%)$, IL-6 (240/240, 100\%), IL-8 (240/240, 100\%), IL-10 (240/240, 100\%), IL-12p70 (211/240, 87.9\%), IL-13 (195/240, $81.3 \%)$, TNF- $\alpha(240 / 240,100 \%)$. Undetectable concentrations were recorded as zero. Non-parametric test showed that the 
Table I. Characteristics of GC patients and controls.

\begin{tabular}{|c|c|c|c|c|}
\hline Variables & GC patients $(\mathrm{n}=142), \mathrm{n}(\%)$ & Controls (n=98), n(\%) & $t / \chi^{2}$ & P-value \\
\hline Age, mean $\pm \mathrm{SD}$ (years) & $63.9 \pm 9.5$ & $63.6 \pm 10.8$ & 0.205 & 0.838 \\
\hline \multicolumn{5}{|l|}{ Sex } \\
\hline Male & $115(81.0)$ & 78 (80.4) & \multirow[t]{2}{*}{0.012} & \multirow[t]{2}{*}{0.912} \\
\hline Female & $27(19.0)$ & $19(19.6)$ & & \\
\hline \multicolumn{5}{|l|}{ Surgery } \\
\hline No & $39(27.5)$ & - & & \\
\hline Yes & $103(72.5)$ & - & & \\
\hline \multicolumn{5}{|l|}{ Lauren classification } \\
\hline Intestinal type & $78(54.9)$ & - & & \\
\hline Diffuse type & $45(31.7)$ & - & & \\
\hline Unknown & $19(13.4)$ & - & & \\
\hline \multicolumn{5}{|l|}{ Preference for fried food } \\
\hline No & $119(85.0)$ & $93(95.9)$ & \multirow[t]{2}{*}{7.183} & \multirow[t]{2}{*}{0.007} \\
\hline Yes & $21(15.0)$ & $4(4.1)$ & & \\
\hline \multicolumn{5}{|l|}{ Preference for salty foods } \\
\hline No & $71(50.7)$ & $81(83.5)$ & \multirow[t]{2}{*}{26.785} & \multirow[t]{2}{*}{$<0.001$} \\
\hline Yes & $69(49.3)$ & $16(16.5)$ & & \\
\hline \multicolumn{5}{|l|}{ Preference for eating fast } \\
\hline No & $76(54.3)$ & 79 (81.4) & \multirow[t]{2}{*}{18.676} & \multirow[t]{2}{*}{$<0.001$} \\
\hline Yes & $64(45.7)$ & $18(18.6)$ & & \\
\hline \multicolumn{5}{|l|}{ Preference for smoking } \\
\hline No & $70(50.0)$ & $77(79.4)$ & \multirow[t]{2}{*}{21.001} & \multirow[t]{2}{*}{$<0.001$} \\
\hline Yes & $70(50.0)$ & $20(20.6)$ & & \\
\hline \multicolumn{5}{|c|}{ Preference for drinking alcohol } \\
\hline No & $85(60.7)$ & $74(77.9)$ & \multirow[t]{2}{*}{7.634} & \multirow[t]{2}{*}{0.006} \\
\hline Yes & $55(39.3)$ & $21(22.1)$ & & \\
\hline \multicolumn{5}{|l|}{ Preference for fresh fruits } \\
\hline No & $85(60.7)$ & $32(33.0)$ & \multirow[t]{2}{*}{17.620} & \multirow[t]{2}{*}{$<0.001$} \\
\hline Yes & $55(39.3)$ & $65(67.0)$ & & \\
\hline \multicolumn{5}{|l|}{ Preference for tea } \\
\hline No & $71(50.7)$ & $39(41.1)$ & \multirow[t]{2}{*}{2.122} & \multirow[t]{2}{*}{0.145} \\
\hline Yes & $69(49.3)$ & $56(58.9)$ & & \\
\hline
\end{tabular}

GC, gastric cancer; SD, standard deviation.

serum seventeen inflammatory cytokines were significantly different between GC patients and controls $(\mathrm{P}<0.05)$, and the exceptions were IL-16, IL-4, and IL-13 (P>0.05; Table II). Logistic expression analysis adjusted by age and sex presented the significantly increased serum IL-12/IL-23P40, IL-15, IL-8 and IL-10 in GC patients compared with healthy controls $(\mathrm{P}<0.05)$. However, stratified analysis showed that the levels of serum inflammatory cytokines were not correlated to the status of surgery (Table SI) or the Lauren classification $(\mathrm{P}>0.05)$ in the GC patients (Table SII). The results hinted that the expressed levels of serum cytokines be affected by GC development and the responding factors.

Relationship between integral score of lifestyle factors and serum inflammatory cytokines. As everyone knows, lifestyle played an important role in the GC development. Here tried to preliminarily analysis the correlation between holistic lifestyle and GC risk. According to the present and previous results (12), five common lifestyle factors (preferring to fried foods, to salty foods, to eating fast, to smoking and to drinking) were regarded as risky factors which could increase the GC risk, while preferring to fresh fruits were regarded as protective factor which could decrease the GC risk. After the integration of the above six lifestyle factors, the results presented that the GC patients had a significantly higher integral score of lifestyle factors than the healthy controls $(\mathrm{P}<0.001$; Table SIII), which were unanimous to Table I. The results further demonstrated that unhealthy lifestyle factors played a key role in GC development. And serum IL-12p70 was observed to be slightly correlated to the score of lifestyle factors in the controls 


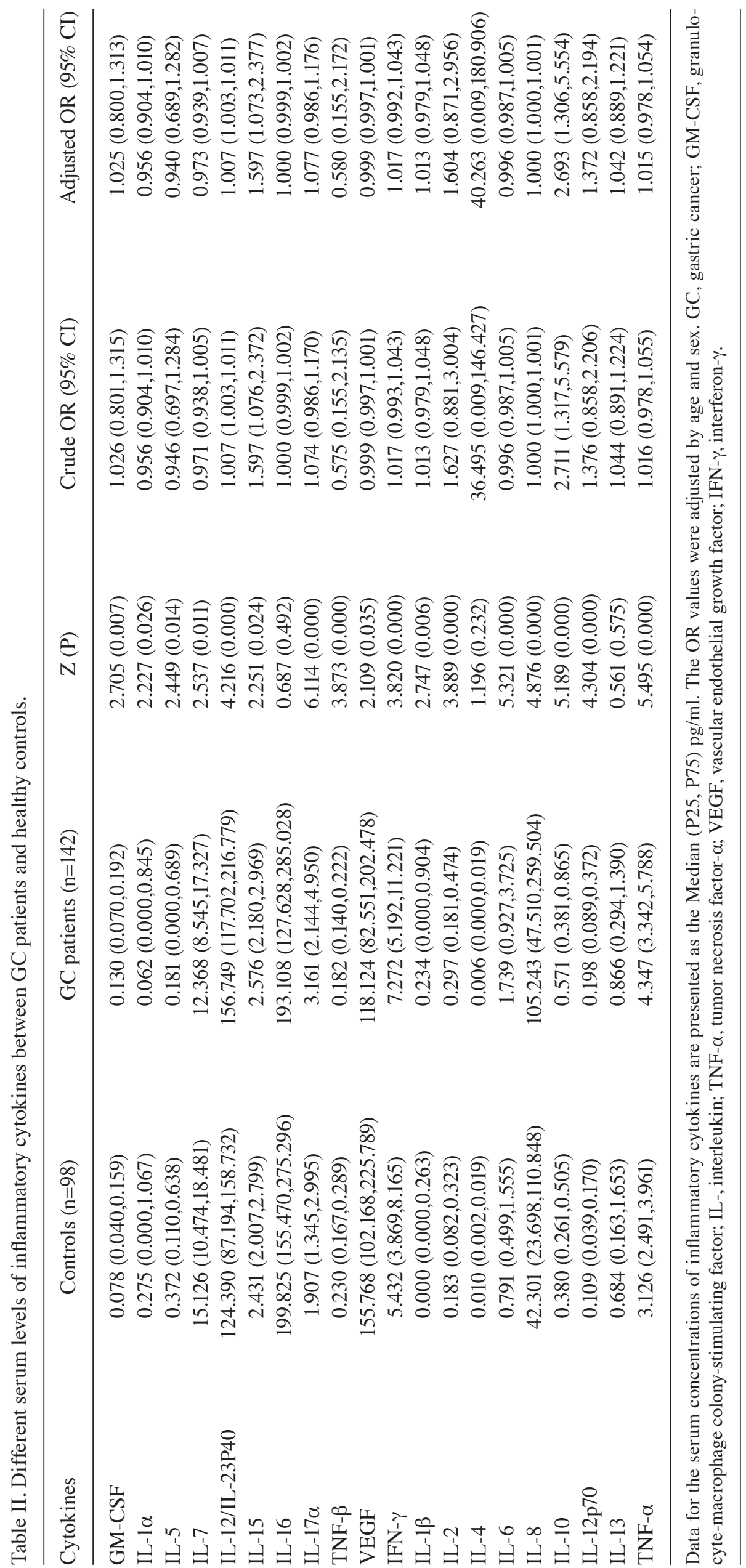




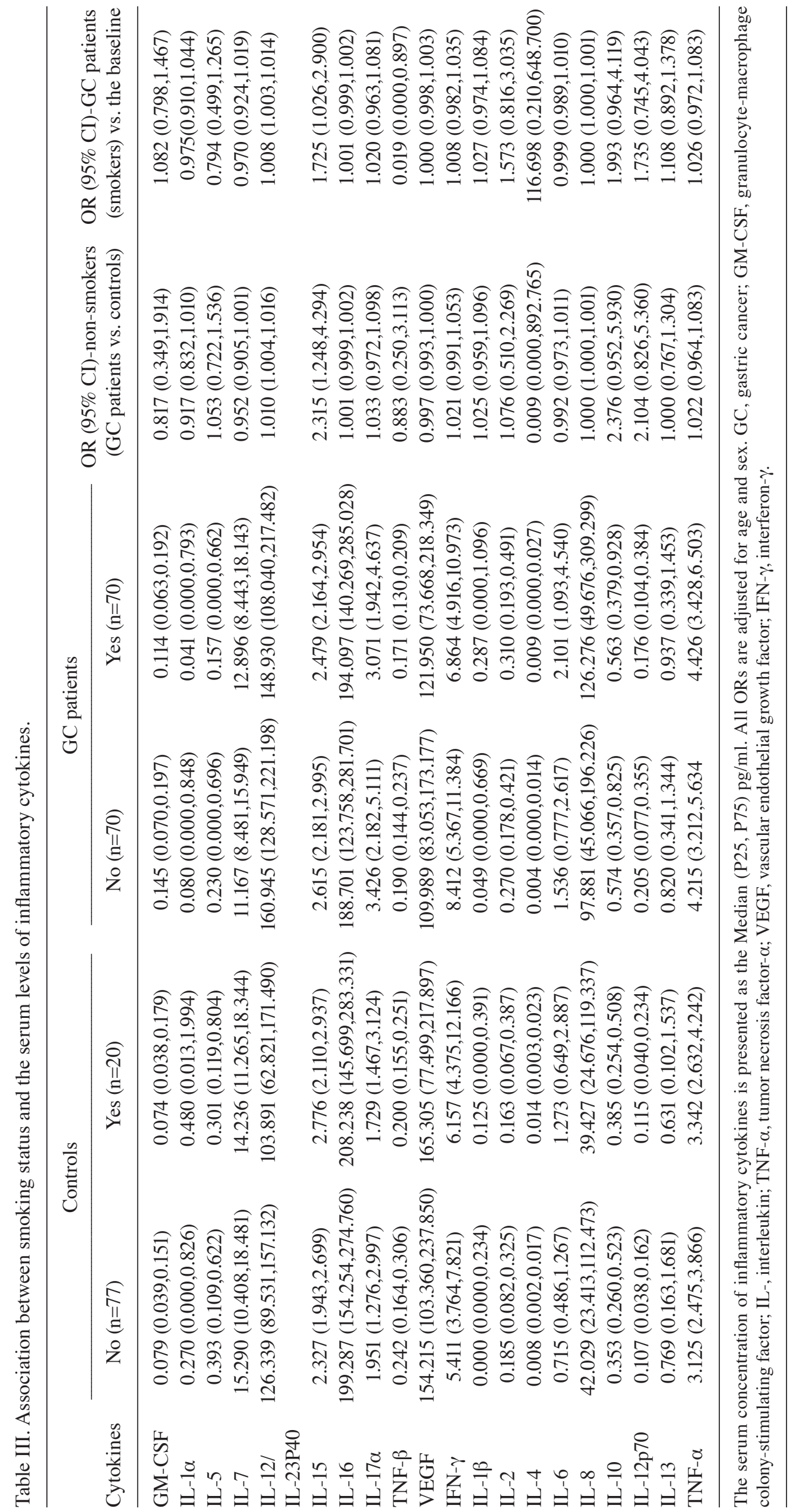


population (Pearson correlation coefficient $=0.250, \mathrm{P}=0.014$ ). However, the results could not tell the relationship between the lifestyle factors and the inflammation. Thus, correlated analysis of the lifestyle factors was conducted as the following.

Relationship between risky lifestyle factors and serum inflammatory cytokines. The present study reconfirmed that the unhealthy lifestyle factors could significantly increase GC risk, i.e., prefer to fried foods, to salty foods, to eating fast, to smoking and to drinking. Due to the serious imbalance of the lifestyle factors disturbance, the controls with healthy lifestyle factors were regarded as baseline to examine the effect of the lifestyle factors on the serum inflammatory cytokines and GC-risk-related lifestyle factors, and the GC patients were divided into two groups with healthy or unhealthy lifestyle factors. Logistic expression analysis adjusted by age and sex was conducted between the GC patients and the controls.

First of all, smoking and drinking were the two most famous factors correlated to GC risk throughout the world. Non-parametric test (Mann-Whitney U test) was used to explore the correlation between the lifestyle factors and serum cytokines in the healthy controls, and the results showed that smoker had a higher level of serum IL-15 than non-smoker $(\mathrm{Z}=2.015, \mathrm{P}=0.044)$, but no differences were observed between drinkers and non-drinkers $(\mathrm{P}>0.05)$. Comparison with the baseline, three serum inflammatory cytokines (IL-12/IL-23P40, IL-15, IL-8) distinctly increased while serum TNF- $\beta$ distinctly decreased in smoking GC patients $(\mathrm{P}<0.05$; Table III). Comparison with the baseline, increased serum IL-12/IL-23P40, IL-15 and decreased serum IL-7 were observed in non-drinking GC patients, while increased serum IL-12/IL-23P40, IL-8 and decreased serum TNF- $\beta$ were observed in drinking GC patients $(\mathrm{P}<0.05$; Table IV).

Secondly, preferring to fried foods and preferring to salty foods were the two characteristic factors which could increase GC risk especially in eastern China. In the healthy controls, preferring to fried foods correlated to the lower levels of $\operatorname{VEGF}(\mathrm{Z}=2.740, \mathrm{P}=0.006)$ and TNF- $\alpha(\mathrm{Z}=2.340, \mathrm{P}=0.019)$ by non-parametric test (Mann-Whitney $U$ test). Comparison with the baseline, increased serum IL-12/IL-23P40, IL-10 and decreased serum IL-7 were observed in GC patients without preferring to fried foods, while increased serum IL-12/IL-23P40, IL-15 were observed in GC patients preferring to fried foods $(\mathrm{P}<0.05$; Table V). Compared with the baseline, five serum inflammatory cytokines (IL-12/IL-23P40, IL-15, IL-17 $\alpha$, IL-8, IL-10) significantly increased in the two GC groups $(\mathrm{P}<0.05)$, but serum IL-7 was significantly decreased in the GC patients preferring to salty foods $(\mathrm{P}<0.05$; Table VI).

Finally, preferring to eating fast could rapidly increase the pressure of the stomach, and cause gastric mucosa injury. Therefore, preferring to eating fast was an important GC risk factor, particularly in the healthy controls, it was observed to be associated with higher concentrations of six serum cytokines including GM-CSF ( $\mathrm{Z}=2.372, \mathrm{P}=0.018), \mathrm{IL}-1 \alpha(\mathrm{Z}=2.492$, $\mathrm{P}=0.013), \mathrm{IL}-1 \beta(\mathrm{Z}=2.207, \mathrm{P}=0.027), \mathrm{IL}-4(\mathrm{Z}=3.119, \mathrm{P}=0.002)$, IL-8 ( $Z=2.069, P=0.039), I L-12 p 70(Z=3.572, P<0.001)$ based on the non-parametric test. Compared with the baseline, five inflammatory cytokines (IL-12/IL-23P40, IL-17 $\alpha$, IL-2, IL-8, IL-10) presented to be outstandingly increased in the two GC groups $(\mathrm{P}<0.05)$, the GC patients without eating fast had significantly lower serum IL-7 and TNF- $\beta$, and the GC patients eating fast had significantly increased serum IL-15, IL-1 $\beta$, and TNF- $\alpha(P<0.05$; Table VII $)$. The results indicated that preferring to eating fast play an important role in the GC development.

Relationship between the protective lifestyle factor and serum inflammatory cytokines. Preferring to fresh fruits was a famous protective factor for GC risk. In the healthy controls, higher level of serum IL-17 $\alpha$ was closely related to the individuals who preferring to fresh fruits $(\mathrm{Z}=1.983, \mathrm{P}=0.047)$. Compared with the baseline, increased serum IL-12/IL-23P40 was observed in the two GC groups $(\mathrm{P}<0.05)$. However, the relationships between GC risk and six serum inflammatory cytokines (IL-7, IL-15, TNF- $\beta$, VEGF, IL-8, IL-10) were distinctly heterogeneous in the two GC groups, the increased serum IL-8, IL-10 and decreased serum IL-7, TNF- $\beta$ were observed in the GC patients without preferring to fresh fruits $(\mathrm{P}<0.05)$, while increased serum IL-15 and decreased serum VEGF were observed in the GC patients preferring to fresh fruits $(\mathrm{P}<0.05$; Table VIII).

\section{Discussion}

In general, the present data showed that GC patients had higher serum levels of IL-12/IL-23P40, IL-15, IL-8 and IL-10 than the controls. The results agreed with the previous data, for examples, one prospective study showed that increased circulating levels of plasma IL-8 may indicate increased GC risk in a Chinese population with high GC incidence and $H p$ prevalence (6), another small scale study showed that the high plasma level of IL-8 were significantly associated with large tumors, deep invasion, lymph node metastasis and shorter disease-free survival (18). In particular, the serum level of IL-12/IL-23P40 significantly increased in the GC patients with protective or risky lifestyle factors compared with the baseline. The results indicated that increased serum IL-12/IL-23P40 be an indifferent helmet of GC-risk because the significant differences were observed in all lifestyle factors. IL-12/IL-23P40 is an important pro-inflammatory cytokine, and animal experiment found that IL-12/IL-23P40 significantly increased during acute schistosomiasis or lipopolysaccharide-stimulation, and arginase I could promote IL-12/IL-23p40-driven gut inflammation, which may promote disruption of the mucosal barrier and leakage of intestinal bacteria and/or LPS into the blood (19). It is well-known that almost all the gut bacteria are gram-negative, and lipopolysaccharide is their famous pathogenic factor. Previous investigation proved the linkage between gut microbial dysbioses and abnormal production of inflammatory cytokines (20). The results indicated that expression level of serum IL-12/IL-23P40 may correlate to gut microbiome at least in GC patients, which was consistent with the opinion that lifestyle exert important influence on gut microbiome during carcinogenesis (21).

As to other inflammatory cytokines, heterogeneous correlations were observed between inflammatory cytokines and lifestyle factors. Thus, the association among lifestyle factors and inflammation was focused on discussion as following. First of all, smoking and drinking were the two most 


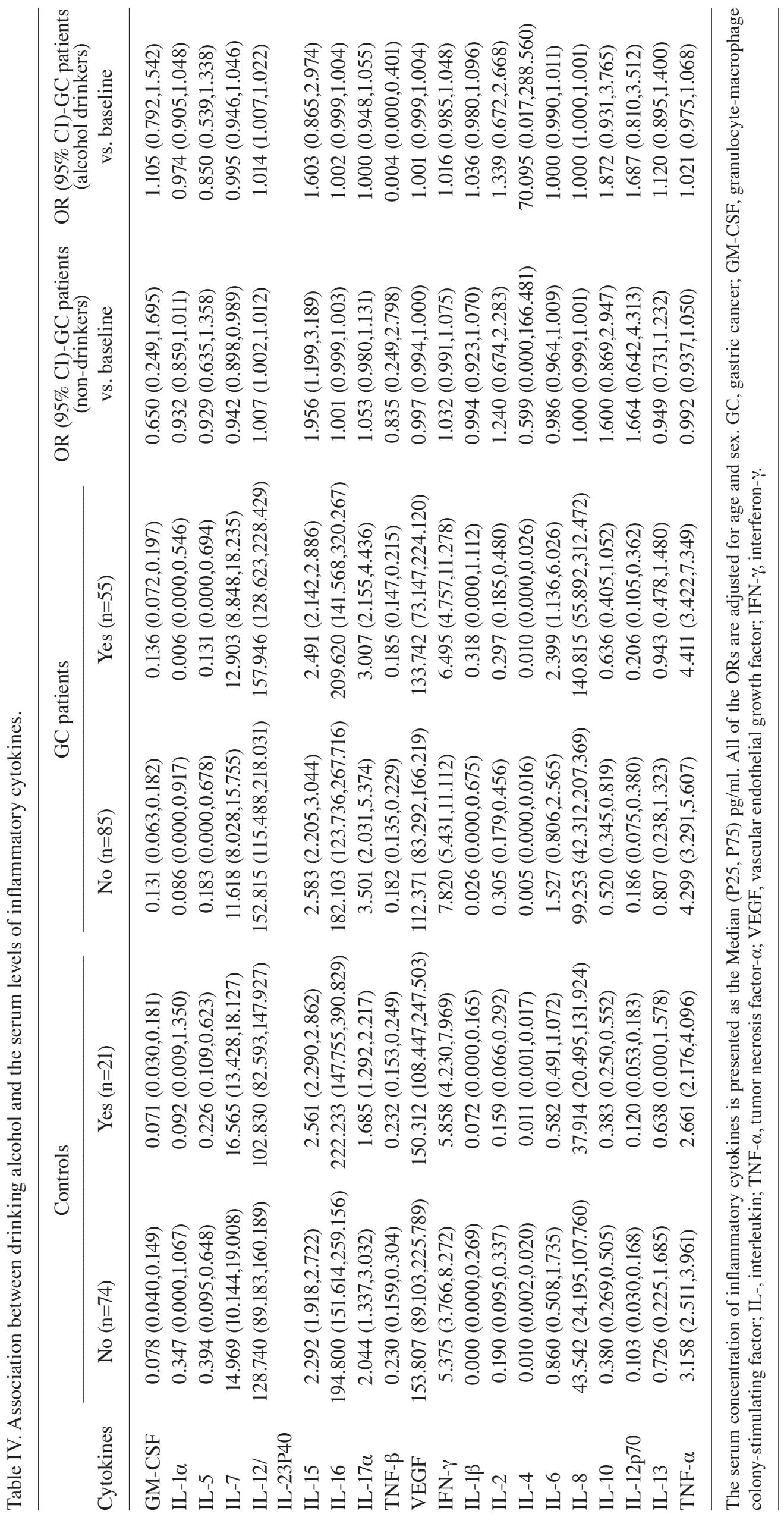




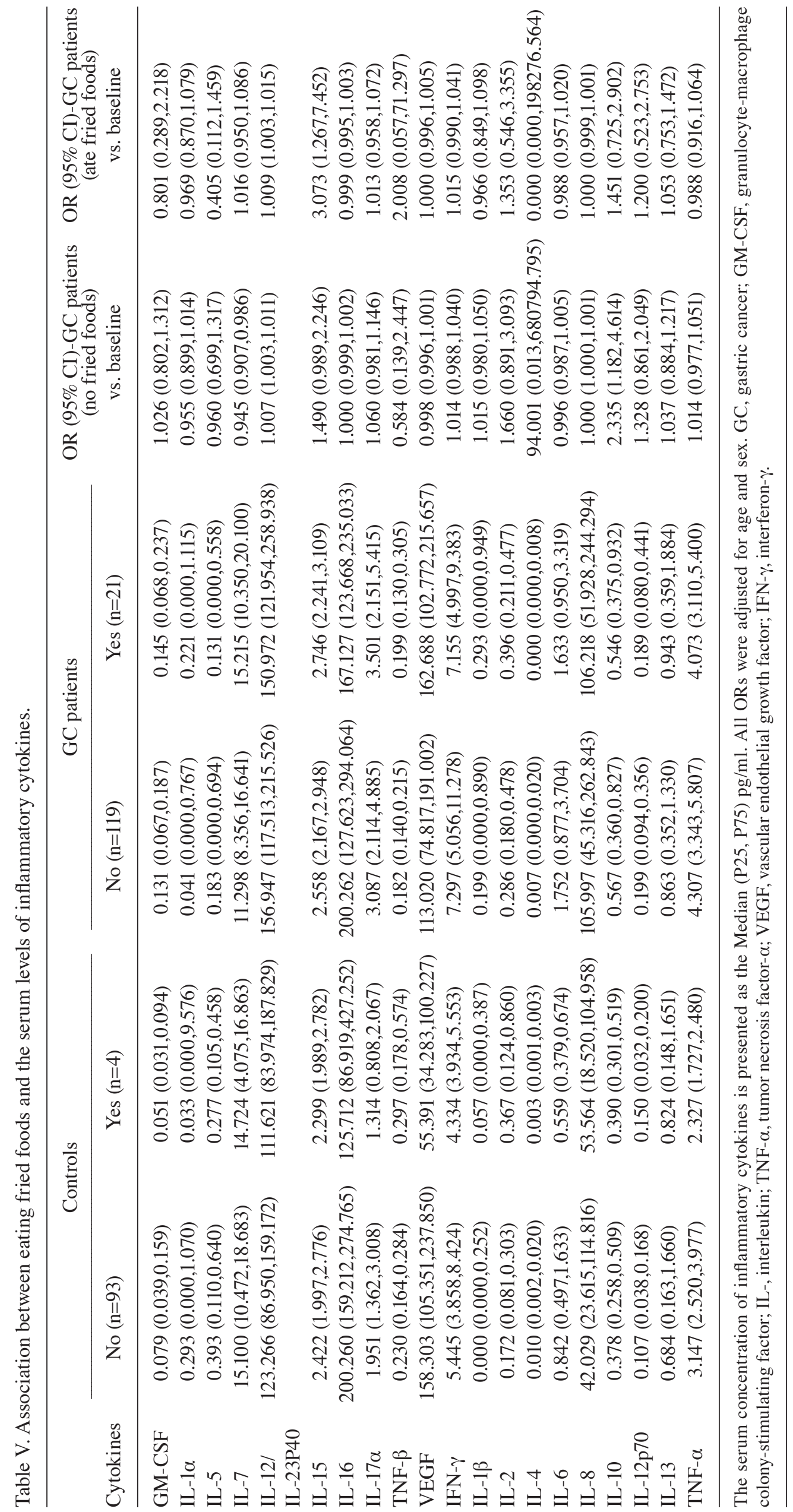




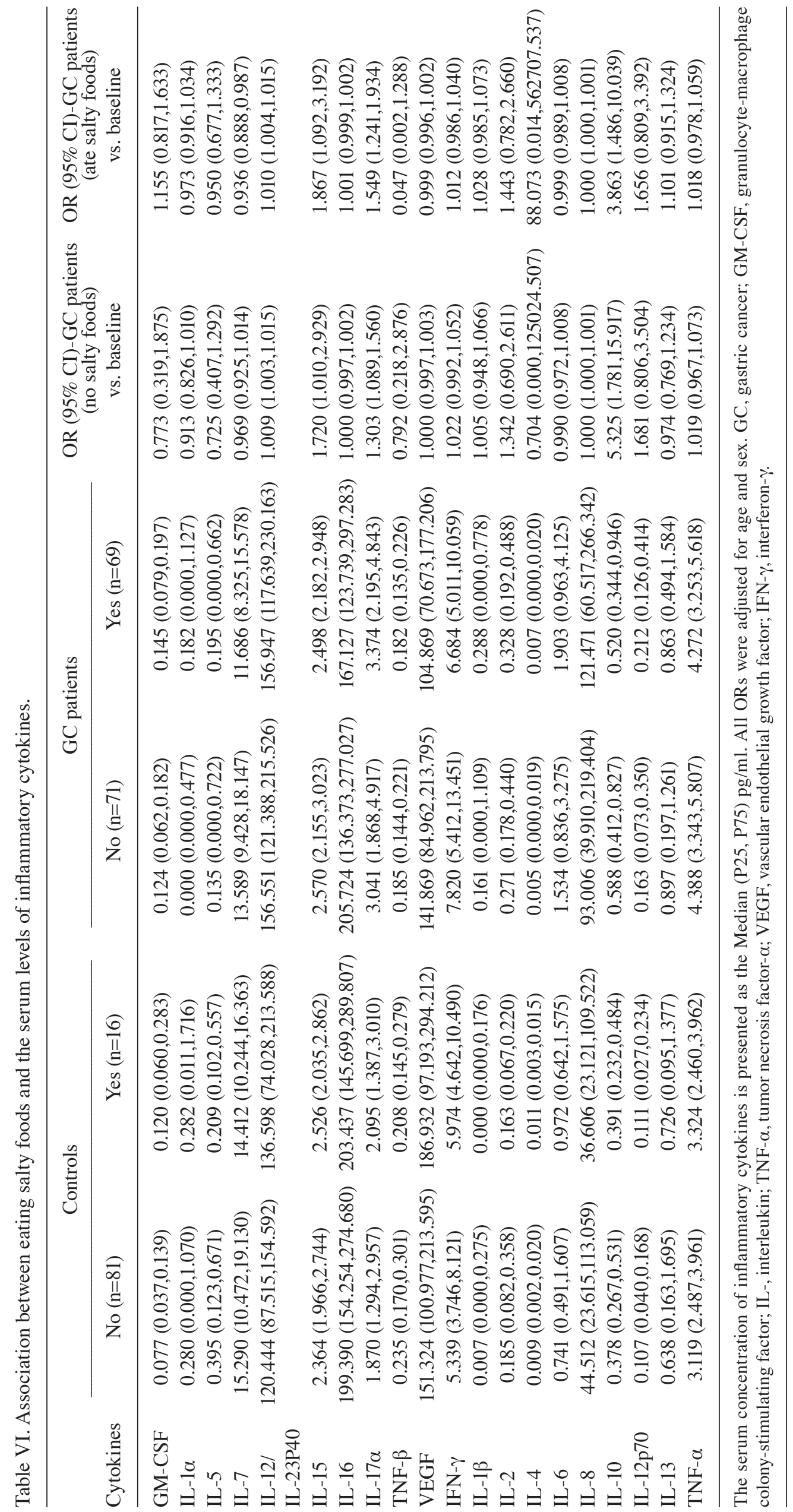




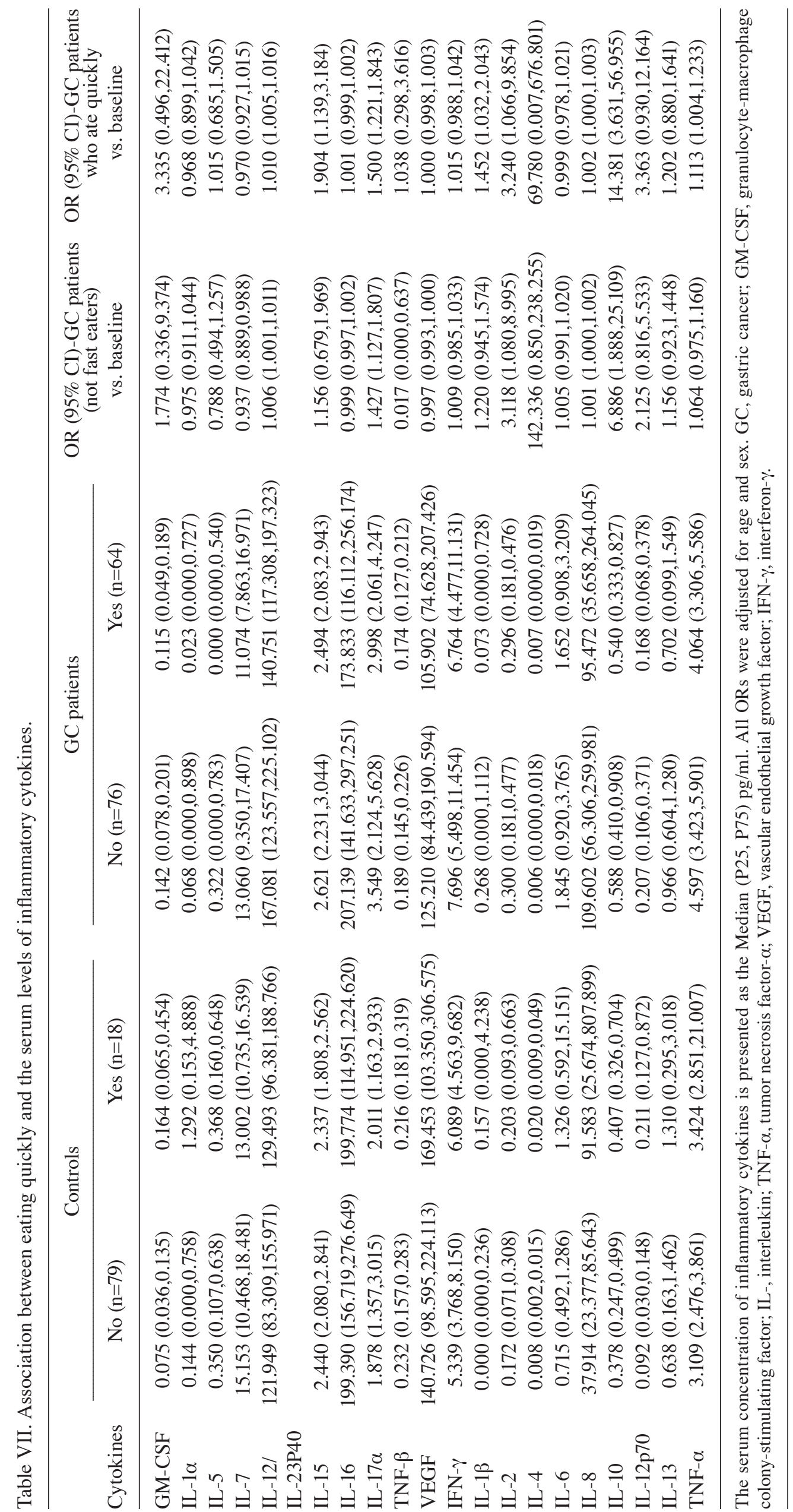




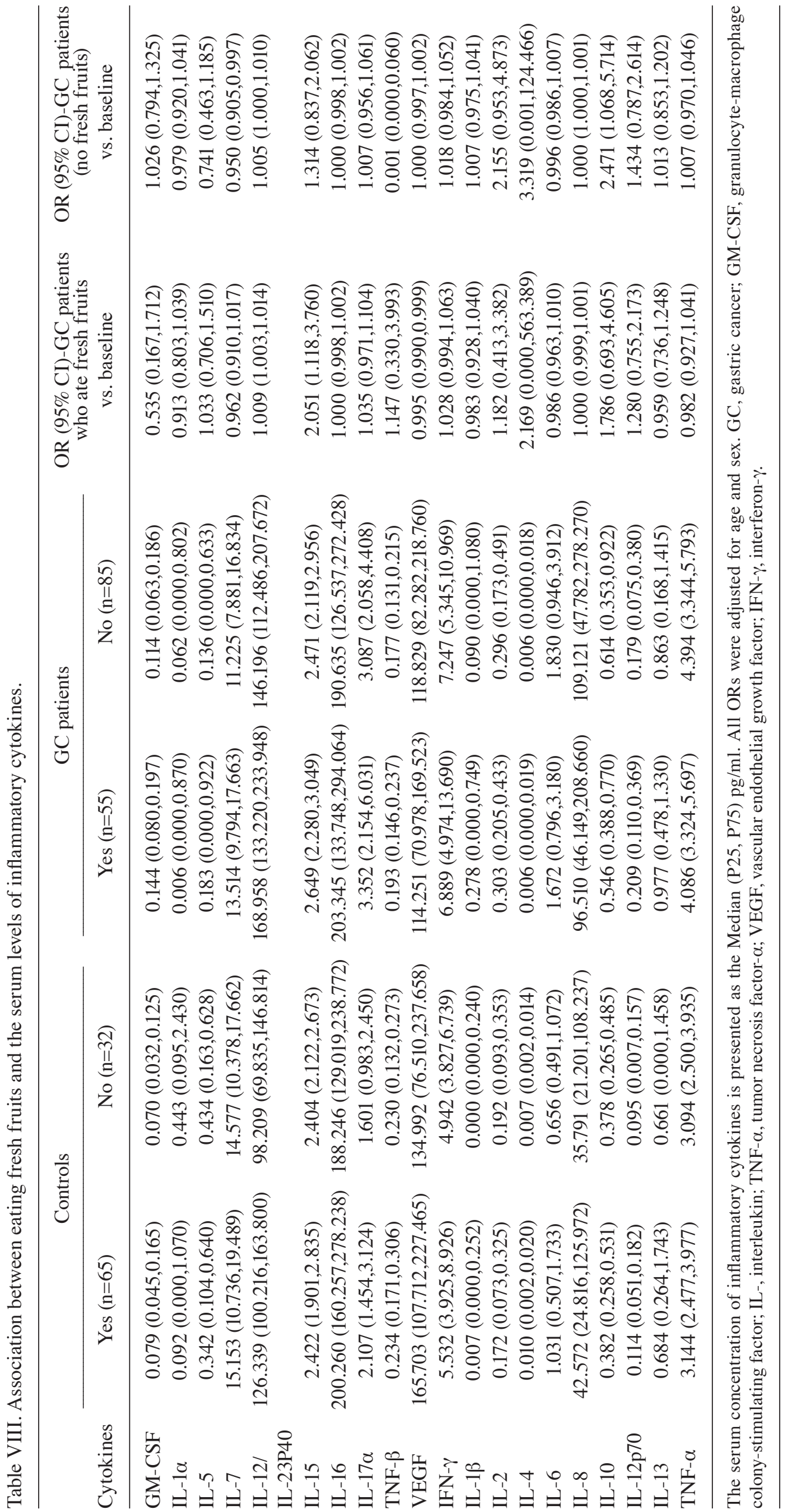


common risk factors for many cancers including GC (22). Previous literatures showed that alcohol could predisposes to atrophic inflammation of the gastric mucosa (23) which was the herald of GC. A randomized clinical trial found that drinking could increase serum IL-10 while could decrease serum IL-16, monocyte chemotactic protein-1 and vascular cell adhesion molecule-1 (24). Even alcohol consumption could induce GC tissues expressing high levels of transcription factor IIB-related factor 1 and myeloperoxidase-positive cell infiltration, which were identified as independent prognostic factors for overall survival (25). Thus, championing of temperance in the high incidence area of GC was necessary. However, the real drinking appeared to have changed considerably, which may explain the different results in the present GC patients.

On the other hand, chronic smoking is characterized by abnormal inflammatory response since the cigarette component have many physiological activities. Clinical study showed that gingival crevicular fluid IL-4, IL-6 and IL-8 were significantly increased in the smoking periodontitis individuals compared with non-smoking periodontitis individuals (26), and smokers with ulcerative colitis had higher serum IL-1 $\beta$ and IL-8 than the non-smokers with ulcerative colitis (27). Experiment in vitro found that cigarette smoke extract (CSE) could promote human macrophage-like cells producing IL-8 and TNF- $\alpha$ (28), and dose-dependently increased IL-8 and IL-6 release in primary human airway epithelial cells (29). Furthermore, IL- 8 could induce angiogenesis and promotes tumor growth, even increased serum IL-8 level can precede the diagnosis of certain cancer (30). These results indicated that IL-8 be closely related to smokers with GC.

Preferring to fried and/or salty foods, eating fast were the characteristic GC risk factors in eastern China. Since both the fried foods and eating fast could damage the mucous membrane of upper digestive tract, this might be the trigger of gastric carcinogenesis. Furthermore, previous review summarized that fat could activate Toll-like receptor 4 (TLR4) signaling pathway and mediate inflammatory events in diabetes (31). Activating TLR4 signaling in dendritic cells and Th17 could induce chronically inflamed tissues producing high levels of IL-15 (32), which may be the reason that GC patients preferring to fried foods had a higher serum IL-15 compared with the baseline. In addition, the fried or salty foods always contain high concentration of salt which is a vital nutrient. However, excess salt intake had been blamed for triggering and/or worsening gastric intestinal metaplasia (33). For example, the latest review proposed that hypertonic saline stimulated overexpression of IL-1 $\beta$, IL-8, TLR3 and TLR4 in macrophage (34). And especially the salt could promote the significant expression of IL-17 $\alpha$ in CD4 T cells (35). These results were consistent to the increased levels of IL-17a, IL- 8 in GC patients preferring to salty foods. In addition, high salt intake could modulate the gut microbiome by Th17 axis (36), which suggested that gut microbiome/IL-15/TLR4 axis be nature of the link between preferring to fried foods and GC risk.

Preferring to fresh fruits but not use of vitamins was the famous protective lifestyle factor against GC (37). Compared with baseline, GC patients lack of fresh fruits had higher serum IL-10, lower serum TNF- $\beta$ and IL-7, however, no differences were observed in GC patients preferring to fresh fruits. The interesting study showed that proliferating $\mathrm{CD} 4^{+}$ regulatory $\mathrm{T}$ cells in GC mucosa could express high level of IL-10 but little TGF- $\beta$ (38), which indicated that preferring to fresh fruits affect the biological behavior of local $\mathrm{T}$ cells in gastric mucosa. It was also presented that increased levels of IL-17 $\alpha$ was related to preferring to eating fast in healthy controls, and IL-17 $\alpha$ was famous named due to its origin from Th17 cells which could produce several effector cytokines (such as IL-17 $\alpha$, IL-17, IL-21, and IL-22) at mucosal sites and played a critical role in mucosal immunity to many extracellular pathogens (39). Thus, fresh fruits might play a role in the inflammatory response of stomach mucosa.

GC development was a long-term and multistep histological cascade, from chronic non-atrophic gastritis that progresses to chronic atrophic gastritis, intestinal metaplasia, and adenocarcinoma. Previous study (40) showed that serum pepsinogen detection could reflect the gastric mucosal status in an Indonesia population. A Japanese cohort study presented (41) that upper gastrointestinal barium X-ray radiography was positively associated with $H p$ infection, current smoking, age, decreased serum pepsinogen I/II ratio, and male sex. Eradication of $H p$ but not intake of gastric acid suppressants seems to superficially improve UGI-XR-based atrophic gastritis. Furthermore, negative $H p$-infection status seemed to be an indicator of poor prognosis in GC patients and was independent of other well-known clinical and pathologic prognostic variables (42). These results provided advanced trains for exploring the effect of lifestyle factors on the GC development, especially the relationship between lifestyle and $H p$ status.

In summary, the main finding was that the lifestyle factors were associated with certain serum inflammatory cytokines, and provided clues for the linking mechanism between GC risk and dietary habits. Of course, since the size of the present population was really not enough big because the investigation was an exploratory research, and the pilot results provided a train of the advanced study, there were still some limitations: The first challenge was the self-reporting lifestyle which was not very reliable, the second point was the complex clinical characteristics which also affect the results stability, the third point was that here did not assay the $H p$ status because several case-control studies showed reverse association $(43,44)$ which indicated that $\mathrm{IgG}$ antibodies to $H p$ contribute little to the effect of lifestyle on serum inflammation, and the final point was that the results require further validation in larger populations or other related biomarkers to disclose the potential inflammatory mechanism of lifestyle factors in development of gastric carcinoma.

\section{Acknowledgements}

The authors would like to thank the following graduates involved in the present study for collecting information and biological samples: Mr. Liwei Zhang (Department of Pathogen and Immunology, School of Medicine and Life Sciences, Nanjing University of Chinese Medicine, Nanjing, China), Miss Rui Wang (Department of Diagnostics of TCM, College of Basic Medicine, Nanjing University of Chinese Medicine), Miss Tao Zhou (Department of Pathogen and Immunology, School of Medicine and Life Sciences, Nanjing University 
of Chinese Medicine) and Miss Yu Zhang (Department of Diagnostics of TCM, College of Basic Medicine, Nanjing University of Chinese Medicine).

\section{Funding}

The present study was supported by the National Natural Science Foundation (grant nos. 81473593 and 81473458). This study was also partly supported by the Project of Clinical Scientific Research of Medicine State Administration of TCM (grant no. JDZX2015089).

\section{Availability of data and materials}

The datasets used and/or analyzed during the present study are available from the corresponding author on reasonable request.

\section{Authors' contributions}

XS and CJX conducted the experiments. JW analyzed the data. WD collected and processed the clinical data. RPW designed and implemented the clinical program. ZZ critically revised the manuscript for important intellectual content. XS and JFZ wrote and revised the manuscript, and JZ designed the study.

\section{Ethics approval and consent to participate}

The research protocol was approved by the Ethics Committee of Jiangsu Province Hospital of TCM (no. 2015NL-016-01). All patients recruited gave written informed consent.

\section{Patient consent for publication}

Not applicable.

\section{Competing interests}

The authors declare that they have no competing interests.

\section{References}

1. Tarver T; American Cancer Society (ACS): Cancer facts and figures 2012. American Cancer Society. J Consum Health Internet 16: 366-367, 2012.

2. Porta C, Riboldi E and Sica A: Mechanisms linking pathogens-associated inflammation and cancer. Cancer Lett 305 : 250-262, 2011

3. Seruga B, Zhang H, Bernstein LJ and Tannock IF: Cytokines and their relationship to the symptoms and outcome of cancer. Nat Rev Cancer 8: 887-899, 2008.

4. Saito H, Tsujitani S, Ikeguchi M, Maeta M and Kaibara N: Relationship between the expression of vascular endothelial growth factor and the density of dendritic cells in gastric adenocarcinoma tissue. Br J Cancer 78: 1573-1577, 1998.

5. Bartchewsky W Jr, Martini MR, Masiero M, Squassoni AC Alvarez MC, Ladeira MS, Salvatore D, Trevisan M, Pedrazzoli J Jr and Ribeiro ML: Effect of Helicobacter pylori infection on IL-8, IL-1 $\beta$ and COX-2 expression in patients with chronic gastritis and gastric cancer. Scand J Gastroenterol 44: 153-161, 2009.

6. Epplein M, Xiang YB, Cai Q, Peek RM Jr, Li H, Correa P, Gao J, Wu J, Michel A, Pawlita M, et al: Circulating cytokines and gastric cancer risk. Cancer Causes Control 24: 2245-2250, 2013.

7. Ichihara F, Kono K, Takahashi A, Kawaida H, Sugai H and Fujii H: Increased populations of regulatory $\mathrm{T}$ cells in peripheral blood and tumor-infiltrating lymphocytes in patients with gastric and esophageal cancers. Clin Cancer Res 9: 4404-4408, 2003.
8. Schneider BG, Camargo MC, Ryckman KK, Sicinschi LA, Piazuelo MB, Zabaleta J, Correa P and Williams SM: Cytokine polymorphisms and gastric cancer risk: an evolving view. Cancer Biol Ther 7: 157-162, 2008.

9. Yang JP, Hyun MH, Yoon JM, Park MJ, Kim D and Park S: Association between TNF- $\alpha-308$ G/A gene polymorphism and gastric cancer risk: a systematic review and meta-analysis. Cytokine 70: 104-114, 2014

10. Compare D, Rocco A and Nardone G: Risk factors in gastric cancer. Eur Rev Med Pharmacol Sci 14: 302-308, 2010.

11. Manoharan S, Kavitha K and Nagini S: Role of life-style on plasma and erythrocyte membrane lipid profile in gastric cancer patients. Indian J Physiol Pharmacol 41: 62-66, 1997.

12. Zhang J, Zhan Z, Wu J, Zhang C, Yang Y, Tong S, Sun Z, Qin L, Yang $\mathrm{X}$ and Dong W: Association among polymorphisms in EGFR gene exons, lifestyle and risk of gastric cancer with gender differences in Chinese Han subjects. PLoS One 8: e59254, 2013.

13. Yassibaş E, Arslan P and Yalçin S: Evaluation of dietary and life-style habits of patients with gastric cancer: a case-control study in Turkey. Asian Pac J Cancer Prev 13: 2291-2297, 2012.

14. Laroiya I, Pankaja SS, Mittal S and Kate V: A study of Helicobacter pylori, infection, dietary pattern and habits in patients with gastric cancer in South India. Asian Pac J Trop Dis 2: $24-26,2012$

15. Lu Y, Shivappa N, Lin Y, Lagergren J and Hébert JR: Diet-related inflammation and oesophageal cancer by histological type: a nationwide case-control study in Sweden. Eur J Nutr 55: 1683-1694, 2016.

16. Breitbart W, Rosenfeld B, Tobias K, Pessin H, Ku GY, Yuan J, Wolchok J: Depression, cytokines, and pancreatic cancer. Psychooncology 3: 339-45, 2014.

17. Peng YH, Xu YW, Guo H, Huang LS, Tan HZ, Hong CQ, Li SS, Xu LY and Li EM: Combined detection of serum Dickkopf-1 and its autoantibodies to diagnose esophageal squamous cell carcinoma. Cancer Med 5: 1388-1396, 2016.

18. Konno H, Ohta M, Baba M, Suzuki S and Nakamura S: The role of circulating IL-8 and VEGF protein in the progression of gastric cancer. Cancer Sci 94: 735-740, 2003.

19. Herbert DR, Orekov T, Roloson A, Ilies M, Perkins C, O'Brien W, Cederbaum S, Christianson DW, Zimmermann N, Rothenberg ME, etal: Arginase Isuppresses IL-12/IL-23p40-driven intestinal inflammation during acute schistosomiasis. J Immunol 184: 6438-6446, 2010.

20. Schirmer M, Smeekens SP, Vlamakis H, Jaeger M, Oosting M, Franzosa EA, Ter Horst R, Jansen T, Jacobs L, Bonder MJ, et al: Linking the human gut microbiome to inflammatory cytokine production capacity. Cell 167: 1125-1136.e8, 2016.

21. Hagland HR and Søreide K: Cellular metabolism in colorectal carcinogenesis: Influence of lifestyle, gut microbiome and metabolic pathways. Cancer Lett 356 (2 Pt A): 273-280, 2015.

22. Sjödahl K, Lu Y, Nilsen TIL, Ye W, Hveem K, Vatten L and Lagergren J: Smoking and alcohol drinking in relation to risk of gastric cancer: a population-based, prospective cohort study. Int J Cancer 120: 128-132, 2007.

23. Bienia A, Sodolski W and Luchowska E: The effect of chronic alcohol abuse on gastric and duodenal mucosa. Ann Univ Mariae Curie Sklodowska Med 57: 570-582, 2002.

24. Chiva-Blanch G, Urpi-Sarda M, Llorach R, Rotches-Ribalta M, Guillén M, Casas R, Arranz S, Valderas-Martinez P, Portoles O, Corella D, et al: Differential effects of polyphenols and alcohol of red wine on the expression of adhesion molecules and inflammatory cytokines related to atherosclerosis: a randomized clinical trial. Am J Clin Nutr 95: 326-334, 2012.

25. Zhang $Y$, Wu H, Yang F, Ning J, Li M, Zhao C, Zhong S, $\mathrm{Gu} \mathrm{K}$ and Wang H: Prognostic value of the expression of DNA repair-related biomarkers mediated by alcohol in gastric cancer patients. Am J Pathol 188: 367-377, 2018.

26. Giannopoulou C, Kamma JJ and Mombelli A: Effect of inflammation, smoking and stress on gingival crevicular fluid cytokine level. J Clin Periodontol 30: 145-153, 2003.

27. Sher ME, Bank S, Greenberg R, Sardinha TC, Weissman S, Bailey B, Gilliland R and Wexner SD: The influence of cigarette smoking on cytokine levels in patients with inflammatory bowel disease. Inflamm Bowel Dis 5: 73-78, 1999.

28. Yang SR, Chida AS, Bauter MR, Shafiq N, Seweryniak K, Maggirwar SB, Kilty I and Rahman I: Cigarette smoke induces proinflammatory cytokine release by activation of NF-kappaB and posttranslational modifications of histone deacetylase in macrophages. Am J Physiol Lung Cell Mol Physiol 291: L46-L57, 2006. 
29. Kode A, Yang SR and Rahman I: Differential effects of cigarette smoke on oxidative stress and proinflammatory cytokine release in primary human airway epithelial cells and in a variety of transformed alveolar epithelial cells. Respir Res 7: 132, 2006.

30. Li XJ, Peng LX, Shao JY, Lu WH, Zhang JX, Chen S, Chen ZY, Xiang YQ, Bao YN,Zheng FJ, et al: As an independent unfavorable prognostic factor, IL-8 promotes metastasis of nasopharyngeal carcinoma through induction of epithelial-mesenchymal transition and activation of AKT signaling. Carcinogenesis 33 1302-1309, 2012.

31. Kim JK: Fat uses a TOLL-road to connect inflammation and diabetes. Cell Metab 4: 417-419, 2006.

32. Harris KM: Monocytes differentiated with GM-CSF and IL-15 initiate Th17 and Th1 responses that are contact-dependent and mediated by IL-15. J Leukoc Biol 90: 727-734, 2011.

33. Dias-Neto M, Pintalhao M, Ferreira M and Lunet N: Salt intake and risk of gastric intestinal metaplasia: Systematic review and meta-analysis. Nutr Cancer 62: 133-147, 2010.

34. Zhang WC, Zheng XJ, Du LJ, Sun JY, Shen ZX, Shi C, Sun S, Zhang Z, Chen XQ, Qin M, et al: High salt primes a specific activation state of macrophages, $\mathrm{M}(\mathrm{Na})$. Cell Res 25: 893-910, 2015.

35. Kleinewietfeld M, Manzel A, Titze J, Kvakan H, Yosef N, Linker RA, Muller DN and Hafler DA: Sodium chloride drives autoimmune disease by the induction of pathogenic TH17 cells Nature 496: 518-522, 2013.

36. Wilck N, Matus MG, Kearney SM, Olesen SW, Forslund K, Bartolomaeus H, Haase S, Mähler A, Balogh A, Markó L, et al: Salt-responsive gut commensal modulates TH17 axis and disease. Nature 551: 585-589, 2017.

37. Fock KM, Talley N, Moayyedi P, Hunt R, Azuma T, Sugano K, Xiao SD, Lam SK, Goh KL, Chiba T, et al; Asia-Pacific Gastric Cancer Consensus Conference: Asia-Pacific consensus guidelines on gastric cancer prevention. J Gastroenterol Hepatol 23: 351-365, 2008.
38. Kindlund B, Sjöling Å, Yakkala C, Adamsson J, Janzon A, Hansson LE, Hermansson M, Janson P, Winqvist $\mathrm{O}$ and Lundin SB: CD4+ regulatory $\mathrm{T}$ cells in gastric cancer mucosa are proliferating and express high levels of IL-10 but little TGF- $\beta$. Gastric Cancer 20: 116-125, 2017.

39. Kolls JK and Khader SA: The role of Th17 cytokines in primary mucosal immunity. Cytokine Growth Factor Rev 21: 443-448, 2010.

40. Miftahussurur M, Nusi IA, Akil F, Syam AF, Wibawa IDN, Rezkitha YAA, Maimunah U, Subsomwong P, Parewangi ML, Mariadi IK, et al: Gastric mucosal status in populations with a low prevalence of Helicobacter pylori in Indonesia. PLoS One 12: e0176203, 2017.

41. Yamamichi N,Hirano C, Shimamoto T,MinatsukiC, Takahashi Y, Nakayama C, Matsuda R, Fujishiro M, Konno-Shimizu M, Kato J, et al: Associated factors of atrophic gastritis diagnosed by double-contrast upper gastrointestinal barium X-ray radiography: a cross-sectional study analyzing 6,901 healthy subjects in Japan. PLoS One 9: e111359, 2014

42. Marrelli D, Pedrazzani C, Berardi A, Corso G, Neri A, Garosi L, Vindigni C, Santucci A, Figura N and Roviello F: Negative Helicobacter pylori status is associated with poor prognosis in patients with gastric cancer. Cancer 115: 2071-2080, 2009.

43. Webb PM, Yu MC, Forman D, Henderson BE, Newell DG, Yuan JM, Gao YT and Ross RK: An apparent lack of association between Helicobacter pylori infection and risk of gastric cancer in China. Int J Cancer 67: 603-607, 1996.

44. Wu J, Lu Y, Ding YB, Ke Q, Hu ZB, Yan ZG, Xue Y, Zhou Y, Hua ZL, Shu YQ, et al: Promoter polymorphisms of IL2, IL4, and risk of gastric cancer in a high-risk Chinese population. Mol Carcinog 48: 626-632, 2009. 